\title{
0 mapeamento da institucionalização dos conselhos gestores de políticas públicas nos municípios brasileiros
}

\author{
Danitza Passamai Rojas Buvinich \\ Universidade Complutense de Madri
}

\begin{abstract}
O Brasil conta, hoje, com mais de 40 mil conselhos gestores de políticas públicas disseminados nos municípios. Entretanto, como estão estruturados e institucionalizados esses espaços que configuram uma ampla rede participativa para o desenvolvimento e implementação de políticas públicas? Tendo como base um modelo classificatório desenvolvido a partir das abordagens teóricas relacionadas com participação social, democracia deliberativa e análise legislativa, este trabalho exploratório identifica as principais características institucionais quanto à obrigatoriedade de conformação, natureza da representação, composição e capacidade decisória; e possíveis padrões regionais na implementação da rede de conselhos. Como resultado, identificou-se que a maioria dos conselhos não é de conformação obrigatória. No entanto, existe uma relação direta entre conformação obrigatória e o grau de implementação das políticas públicas municipais. Identificaram-se, também, padrões de conformação institucionais regionais diferenciados: os conselhos da região Nordeste são proporcionalmente mais paritários e deliberativos do que os das regiões Sul e Sudeste. Por último, a análise transversal dos dados aponta uma tendência de alteração no modelo institucional de conselhos brasileiros.
\end{abstract}

PALAVRAS-CHAVE: participação social; participação política; conselhos gestores de políticas e programas.

El mapeo de la institucionalización de los consejos gestores de políticas públicas en los municipios brasileños

En la actualidad, Brasil tiene más de 40 mil consejos gestores de políticas públicas distribuidos en los municipios. Sin embargo, ¿̇cómo están estructurados e institucionalizados estos espacios que forman una amplia red participativa para el desarrollo y la implementación de políticas públicas? Teniendo como base un modelo clasificatorio desarrollado desde abordajes teóricos relacionados con la participación social, la democracia deliberativa y el análisis legislativo, este trabajo exploratorio identifica las principales características institucionales con relación a la obligatoriedad de conformación, la naturaleza de la representación, la composición y la capacidad decisoria; y posibles patrones regionales en la implementación de la red de consejos. Como resultado, se identificó que la mayoría de los consejos no es de conformación obligatoria. Sin embargo, hay una relación directa entre obligatoriedad de conformación

Artigo recebido em 25 out. 2012 e aceito em 4 out. 2013. 
y el grado de implementación de las políticas municipales. También fueron identificados patrones de conformación institucionales regionales diferenciados: los consejos de la región Nordeste son más paritarios y deliberativos que los de las regiones Sur y Sudeste. Por último, el análisis transversal de los datos apunta una tendencia de cambio en el modelo institucional de consejos brasileños.

Palabras clave: participación social; participación política; consejos gestores de políticas y programas.

Mapping of the institutionalization of councils for managing public policies in Brazilian towns Currently, Brazil has more than 40,000 councils for managing public policies spread throughout towns. However, how are structured these spaces that constitute a broad participatory network for developing and implementing public policies? Having as a basis a classificatory model developed through theoretical approaches related to social participation, deliberative democracy, and legislative analysis, this exploratory paper identifies the main institutional characteristics concerning mandatory conformation, nature of the representation, composition, and decision-making capacity; and possible regional patterns in the implementation of the councils network. As a result, we identified that most councils do not have mandatory conformation. Nevertheless, there is a direct relationship between mandatory conformation and the implementation degree of municipal public policies. We also identified unique regional institutional conformation patterns: councils in the Northeast region are proportionately more balanced and deliberative than those in the South and Southeast regions. Finally, the cross-sectional data analysis points out a tendency for change in the institutional model of Brazilian councils.

KEYWORDs: social participation; political participation; councils for managing policies and programs.

\section{Introdução}

A pulverização do modelo de gestão de políticas e programas públicos por meio de conselhos, no Brasil e no mundo, não é novidade. Vários estudos têm procurado descrever de forma aprofundada as especificidades de seu funcionamento.

A dificuldade nesta seara se funda não na falta de informação, mas na organização e sistematização do vasto conhecimento já produzido. Aliada a isto está a dimensão do país objeto de análise, que faz com que as diversidades econômicas, políticas, administrativas e culturais sejam enormes, e imediatos seus reflexos nos modelos institucionais.

Analisar como estão sendo implantados os conselhos de políticas e programas nos municípios brasileiros possibilita formar uma visão sistêmica ampla, raramente fornecida nos estudos sobre o tema, que buscam em geral enfocar uma área temática específica, ou uma região determinada.

Ademais, a influência que os desenhos institucionais podem ter nos resultados produzidos pelos conselhos faz com que o conhecimento da conformação dessa rede seja elemento estratégico fundamental para a avaliação do modelo de participação em si.

Nesse sentido, identificar as características institucionais gerais e possíveis padrões regionais pode contribuir para a identificação de desenhos mais adequados a contextos culturais e políticos específicos, direcionando a implementação de modelos mais aptos a produzir resultados mais efetivos. 
Para isso, a pesquisa empreendida buscou responder à seguinte pergunta-problema: Quais são as características gerais de implantação dos conselhos de políticas e programas nos municípios brasileiros?

Para alcançar este objetivo, o trabalho foi dividido em duas partes: a primeira teve por finalidade um levantamento normativo geral, capaz de identificar quais políticas públicas brasileiras utilizam o conselho como método de gestão das respectivas políticas; em seguida buscou-se identificar as principais características institucionais dos conselhos, ou seja, os principais elementos de seu funcionamento, a partir da análise do referencial teórico de participação, especialmente o referente à democracia deliberativa, para então montar o seguinte quadro classificatório que tornasse possível a análise dos dados empíricos.

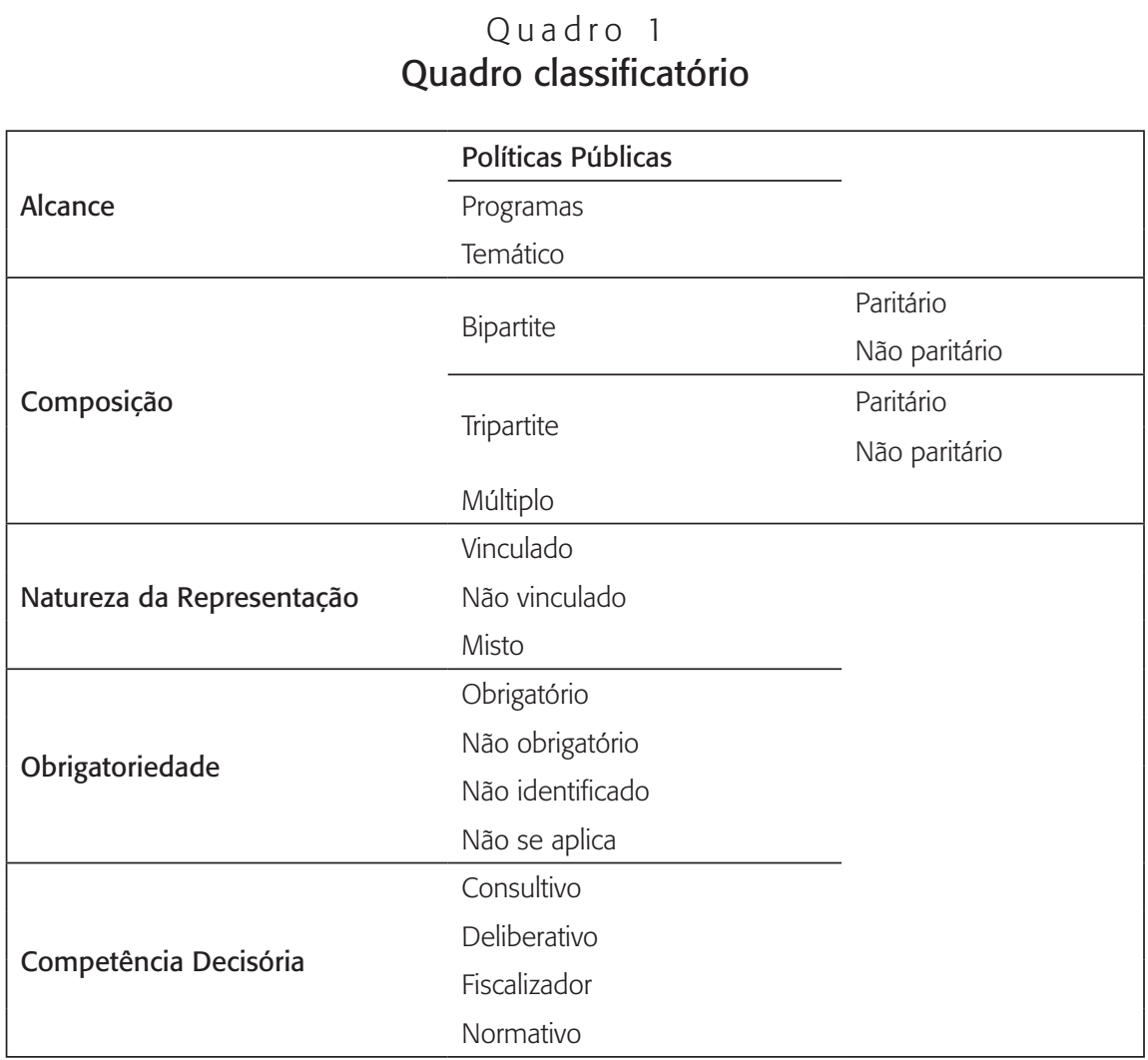

Fonte: Elaboração própria a partir da análise teórica de referências diversas.

Ainda que o foco do trabalho seja a estrutura municipal de conselhos, considerou-se necessária a realização de levantamento prévio da estrutura federal, para então proceder-se à análise dos conselhos municipais, já que a normatização da estrutura de gestão colegiada advém das leis federais que instituem as políticas setoriais, ainda que possam existir norma- 
tizações complementares de estados e municípios. ${ }^{1}$ Esta análise viabilizou também a identificação de mudanças no padrão de conformação dos conselhos federais nos último anos, bem como apontou a diretriz participativa do governo do PT, elementos de importância na análise macrossistêmica da institucionalização dos espaços participativos.

Para identificação dos conselhos federais utilizou-se como principal critério a relação oficial disponibilizada pela Secretaria Nacional de Articulação Social da Presidência da República (Brasil, 2010). A obra, no entanto, apresenta inconsistências. Inicialmente porque a publicação deixa de fora quatro conselhos que reúnem as mesmas características dos demais, mas não são mencionados: Conselho Nacional do Trabalho, regulamentado pelo Decreto $\mathrm{n}^{\circ}$ 1.617/1995; Conselho Deliberativo do Fundo de Amparo ao Trabalhador (FAT), criado pela Lei no 7.998/1990 e regulamentado pelo Decreto no 6.827/2009; Conselho Deliberativo da Política do Café, regulamentado pelo Decreto no 4.623/2003 e o Conselho Nacional de Política Agrícola, pelo Decreto n⿳ 5.741/2006. Ademais, há um equívoco na informação sobre a lei criadora do Conselho Nacional de Deficientes (Conade).

Considerando que a publicação não foi suficiente para determinar todas as características definidas no modelo classificatório, foi necessário realizar pesquisa nas legislações específicas de todos os 36 conselhos. Muitas vezes a informação não estava especificada na lei de criação do conselho, mas na lei que instituiu a política ou o programa. Para tanto utilizou-se o portal eletrônico de legislação federal da Presidência da República: <www. planalto.gov.br $>$. Em alguns casos, além de consultar a legislação federal, foi também necessária a consulta aos portais específicos dos conselhos para localização de normas internas, portarias e resoluções.

Especificamente quanto à sistematização quantitativa dos conselhos de políticas públicas, o trabalho se baseou na publicação Levantamento de informações básicas municipais realizado pelo Instituto Brasileiro de Geografia Estatística (IBGE) em 2009 (IBGE, 2010). Para estabelecimento da relação de proporcionalidade em nível regional (agregação regional dos dados) foram realizados cálculos de regra de três simples. Os padrões de análise se repetem nas distintas áreas, mantendo-se inalterada a forma de cálculo.

Definido o escopo e objetivos, cabe destacar os seguintes recortes limitativos:

Os conselhos gestores analisados são somente aqueles constantes de políticas e programas executados pelo Poder Executivo. Eventuais conselhos implementados no âmbito do Poder Judiciário ou Legislativo não estão abrangidos por esta análise.

Não foram objeto da pesquisa os mecanismos de participação social não institucionalizados. Isso significa que não estão incluídas as diversas associações da sociedade civil brasileira, mas tão somente os conselhos de políticas e programas legalmente institucionalizados pelo Executivo federal e municipal.

\footnotetext{
${ }^{1}$ Vale observar que o intuito inicial da pesquisa era realizar um levantamento da estrutura de conselhos nos três níveis de governo: federal, estadual e municipal. Ocorre que, à época de realização da pesquisa, o IBGE não dispunha de dados dos conselhos estaduais. Somente no início de 2013, o IBGE divulgou informações parciais na publicação Estadic.
} 
Por fim, cabe mencionar que os conselhos estaduais não foram analisados em razão da falta de dados oficiais disponibilizados pelo IBGE à época da pesquisa (2011-12).

\section{Especificação teórica dos elementos classificatórios}

A definição de tipologias classificatórias, para organização dos dados a serem coletados, per $s e$, já foi um primeiro grande desafio. Isso porque os autores não possuem, de maneira geral, uma precisão no uso das terminologias, o que faz com que seja necessário mapear os distintos termos e seus significados.

Ademais, poucos são os autores que aprofundam o debate sobre elementos classificatórios. Aqueles que o fazem, possuem um intuito muito mais didático, para apresentação dos dados dos quais dispõem, do que efetivamente doutrinário propositivo. Dessa maneira, as tipologias classificatórias variam em razão da proposta do autor.

No entanto, está bastante presente na bibliografia a distinção dos conselhos por alcance: de políticas públicas, de programas ou temáticos. Essa terminologia classificatória foi utilizada em 1997, pelo Instituto de Pesquisa Econômica Aplicada (Ipea), na publicação Comunidade solidária, sendo adotada em seguida por diversos autores, como Tatagiba (2002).

Assim, consideram-se conselhos de Políticas Públicas aqueles “(...) ligados às políticas públicas mais estruturadas ou concretizadas em sistemas nacionais" (Ipea, 1997, apud Tatagiba, 2002). Tais conselhos estão previstos na legislação, geralmente considerada "Lei Orgânica", como parte de um sistema de gestão amplo, que integra as três esferas da federação.

Seriam de programas os conselhos "vinculados a programas governamentais" (Ipea, 1997, apud Tatagiba, 2002). Estes "em geral articulam ou acumulam funções executivas no âmbito de seu respectivo programa. Trabalham mais com a noção de clientelas específicas, supostamente beneficiárias do programa" (Tatagiba, 2002:49).

Os conselhos temáticos "sem vinculação imediata a um sistema ou legislação nacional (...), em geral, se associam a grandes movimentos de ideias ou temas gerais, que (...) por alguma peculiaridade de perfil político ou social acolhem ou enfatizam o referido tema" (Tatagiba, 2002:49).

Os conselhos também podem ser classificados conforme sua forma de intervenção em: consultivos, normativos e deliberativos. O Instituto Brasileiro de Geografia Estatística (IBGE, 2010) utiliza ainda o termo "fiscalizador". Tal tipologia classificatória pode ser assim ilustrada:

As características apresentadas nas colunas 1 e 2 do esquema são determinantes e não permitem combinação entre elas; enquanto as características apresentadas na coluna 3 podem ser combinadas entre si. Isso significa que um conselho de políticas públicas, de âmbito municipal, pode ser deliberativo, consultivo, normativo e fiscalizador ao mesmo tempo. 
Quadro 2

Tipologias dos conselhos

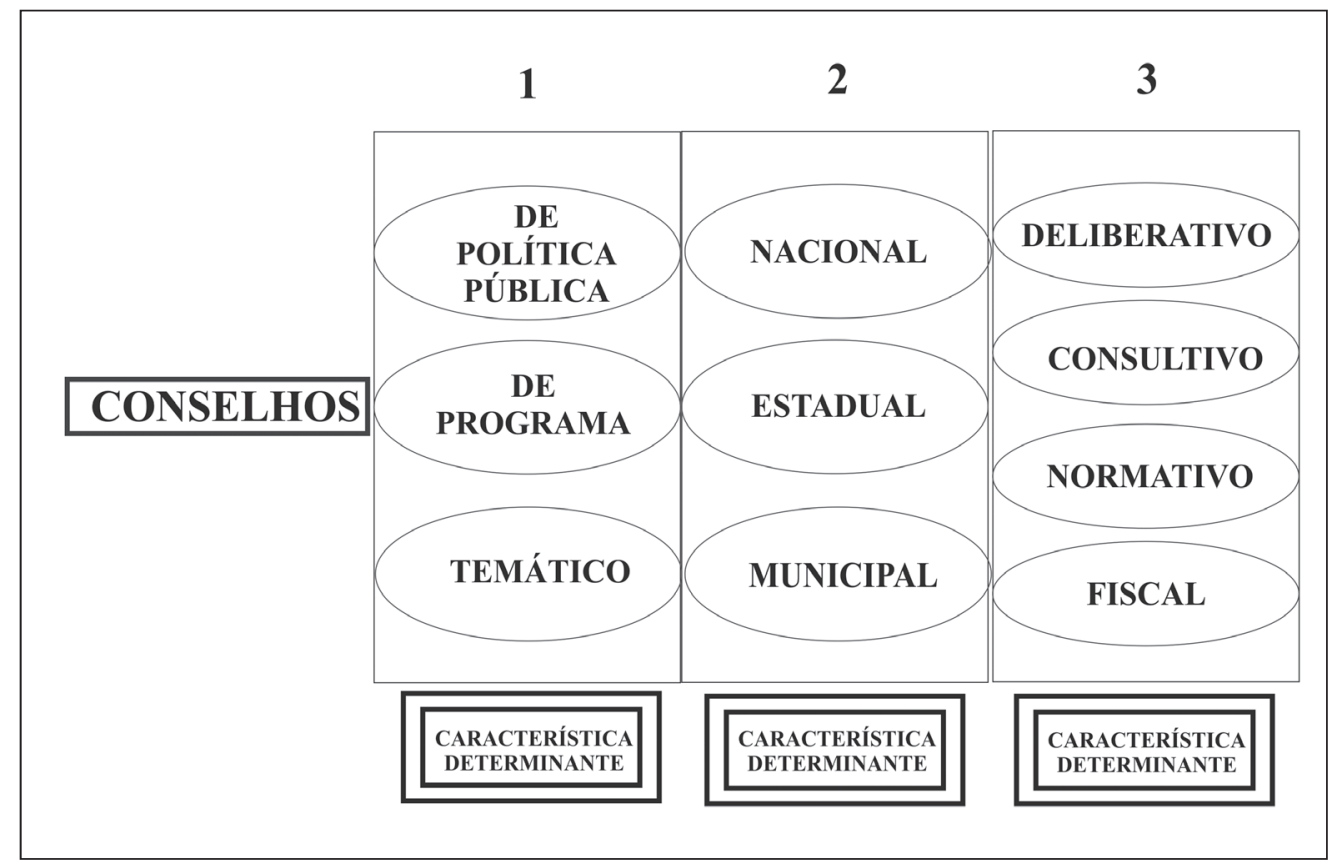

Fonte: Elaboração própria a partir de consultas diversas.

Provavelmente, o trabalho de classificação mais sólido já publicado seja o de Draibe (1998). A autora propõe a classificação dos conselhos de acordo com a natureza da representação, da participação e de composição:

1) Quanto à representação: os conselhos podem ter representações vinculadas, não vinculadas; representação mista, ou ainda, vinculada funcional.

a) Representação vinculada: "a representação das categorias sociais ou profissionais se faz através de organizações da sociedade civil, que indicam seus representantes" (Draibe, 1998:10), ainda que os critérios de indicação variem.

b) Representação vinculada funcional: os membros são indicados por ocuparem um determinado cargo. Assim, a indicação se faz em razão do cargo e não da pessoa.

c) Representação não vinculada: os membros são indicados em razão da expressão de seu trabalho na sociedade (seja no meio acadêmico ou empresarial). Sua indicação decorre diretamente de convite do governo, "ou através de processos não vinculantes, nos quais são ouvidos os pares".

d) Representação mista: convivem no conselho a representação vinculada e não vinculada. 
2) Quanto à natureza da participação: os conselhos podem ser consultivos ou deliberativos. $\mathrm{Na}$ análise realizada nos conselhos existentes à época pela autora foi identificada a tendência de se ter conselhos deliberativos quando o tipo de representação era vinculada.

3) Quanto à composição os conselhos podem ser:

a) Bipartites e paritários: formados por governo e sociedade civil com o mesmo número para cada segmento;

b) Bipartites e não paritários: formados por membros governamentais e da sociedade civil, sem equivalência entre ambos;

c) Tripartites e paritários: estão presentes membros do governo, dos trabalhadores ou usuários, empregadores ou prestadores de serviços, sendo equivalente o número entre cada categoria;

d) Múltiplos e não paritários: governo, trabalhadores ou usuários, empregadores ou prestadores de serviço e por vezes representantes de determinados segmentos da sociedade civil, como especialistas.

A autora não menciona, mas vale incluir um tipo identificado neste trabalho, que são os conselhos tripartites não paritários, como é o caso emblemático da saúde. Nele há representantes do governo, dos trabalhadores e dos usuários.

Outro importante elemento que deve ser incluído como característica para classificação é a obrigatoriedade de implantação de conselhos estaduais e municipais, pois ainda que muitos autores levem a crer que a maioria dos conselhos é de formação obrigatória, ao analisar a legislação específica tal fato não se concretiza.

O enfoque nessas tipologias classificatórias (natureza da representação, composição, paridade, capacidade decisória, bem como a obrigatoriedade) se justifica nas teorias sobre participação social, especialmente a teoria sobre democracia deliberativa.

Nesse sentido, partimos da contribuição de Avritzer (2000) com sua interpretação sobre o desenvolvimento da teoria da democracia deliberativa, que foca justamente o debate sobre o processo deliberativo nos espaços públicos, a partir dos trabalhos de Habermas, Cohen e Bohman. ${ }^{2}$

A teoria deliberativa agrega a participação, mas vai além ao focar não somente o processo participativo, mas os resultados que podem ser extraídos da participação. Neste sentindo, a deliberação ganha importância, pois seria o resultado concreto da multiplicidade de interesses sociais confluindo com um propósito específico.

Para chegar então ao resultado, a participação, a argumentação pública, o respeito à multiplicidade ideológica e a racionalidade pública seriam elementos condicionantes e neces-

\footnotetext{
${ }^{2} \mathrm{O}$ presente artigo não tem por objetivo ampliar as discussões teóricas por trás de cada elemento classificatório. Para aprofundamento nas teorias consultar: Bohman e Rehg (1997); Cohen e Sabel (1997); Deepening Democracy, de Fung e Wright (2003).
} 
sários a um processo deliberativo capaz de ser legítimo. A deliberação ocorreria em um locus, ao qual Habermas nomeou de esferas públicas.

Cohen numera três condições necessárias para se obter uma verdadeira democracia deliberativa: permitir e encorajar inputs fundamentados na experiência local e na informação; oferecer avaliações disciplinadas de propostas recebidas e criar espaços de participação institucionalizados e regulamentados. As três propostas de operacionalização da democracia deliberativa formam o que o autor chama de Poliarquia Diretamente Deliberativa (PDD).

Cohen propõe que decisões podem ser legítimas ainda que não sejam um consenso. $\mathrm{O}$ argumento utilizado pelo autor é de que a legitimidade está no processo de discussão, que deve ser inclusivo, ainda que a deliberação seja por maioria. Garantindo a legitimidade do processo, garantir-se-ia seu resultado.

Aliada à discussão sobre a necessidade do consenso está a questão da representação. Especialmente porque a teoria deliberativa foca a legitimidade ao processo de discussão orientado pelos princípios da inclusão, do pluralismo, da igualdade participativa, da autonomia e do bem-comum. Como garantir esses princípios dentro de um modelo representativo?

Conforme analisa Luchmann (2007), a distinção da representação no interior da participação se dá pelo fato de esta ser uma representação coletiva, pautada na ideia da mediação. Como explicita:

difere de configurar-se apenas como a vocalização difusa de causas diversas, na medida em que "desempenha também funções de intermediação perante o poder público na forma de representação virtual, ou seja, da defesa de interesses que não autorizaram essa defesa ou que, embora simpáticos a ela, carecem de qualquer mecanismo estável para controlá-la ou comunicar-lhe preferências" (Gurza Lavalle, Houtzager e Castello, 2006a:92). De alguma forma, subjaz aqui a dimensão do compartilhamento de olhares e perspectivas entre representantes e representados, embora não necessariamente compartilhem as mesmas posições na estrutura social. (Luchmann, 2007:164)

Assim, a representação no interior da participação, além de configurar-se legítima e necessária à implementação ampliada de espaços públicos de deliberação, traz consigo uma concepção distinta: a de representação de causas e ideias.

Os teóricos da deliberação entendem que a finalidade da participação política seja a capacidade efetiva de direcionar as decisões das autoridades políticas. Os debates contemporâneos têm se centrado na discussão de modelos institucionais capazes de efetivamente possibilitar um processo de participação deliberativa.

Avritzer (2009) propõe que o sucesso da implantação de um modelo participativo estaria relacionado ao desenho institucional empregado nos espaços de participação. De acordo com o autor, o desenho institucional seria o elemento central na estrutura de participação brasileira, que teria sido influenciada ainda por outros dois elementos: cultura cívica e contexto político. Estes teriam criado uma condição adequada para a interação bem-sucedida entre a sociedade civil e política. 
Assim, tendo por base tais argumentos teóricos, justifica-se a determinação dos elementos classificatórios anteriormente elencados, em razão de sua estreita relação com as avaliações de efetividade deliberativa, e com o cumprimento do papel democratizador destacado pelos conselhos; ademais, são estas as características variáveis que fazem que as distinções de implementação sejam tão acentuadas.

Destarte, a partir da caracterização da configuração estrutural dos conselhos com base nesses elementos classificatórios ora determinados foi possível identificar os padrões regionais a seguir especificados.

\section{Apresentação e análise dos dados levantados}

\subsection{Conselhos federais}

Como mencionado, para que se pudesse proceder à análise dos conselhos municipais, inicialmente foi mapeada a estrutura dos conselhos federais.

Dessa análise, constatou-se que atualmente existem 36 conselhos federais, com as características institucionais expostas no quadro 3 (anexo). ${ }^{3}$

Desses dados, verifica-se que a maior parte dos conselhos existentes, 44\%, foi criada entre 2003 e 2010; enquanto 38\% foram criados entre 1990 e 2002, e apenas 16\%, o equivalente a seis conselhos, foram criados antes de 1990, conforme se verifica no gráfico 1.

\section{Gráfico 1}

Período de criação dos conselhos federais

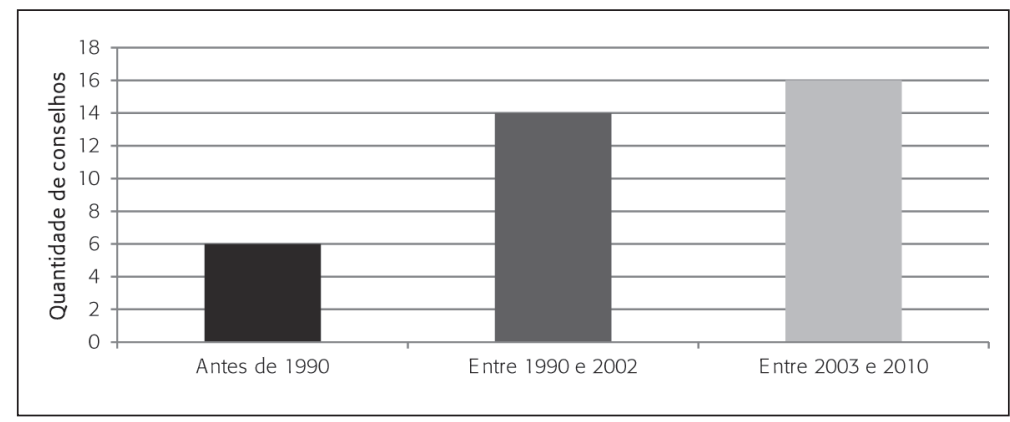

Fonte: Buvinich (2012).

Interessante notar o fato de a maioria dos conselhos criados antes de 1990 ser de décadas anteriores à nova Constituição de 1988. A distinção é que esses conselhos, ainda que

\footnotetext{
${ }^{3}$ A pesquisa foi desenvolvida no período de 2011-12 e refere-se a dados do ano de 2011.
} 
criados há muitos anos, tinham competências distintas, servindo mais como "conselho de notáveis", de caráter consultivo, do que um espaço de participação social, nos moldes atuais.

Outra informação interessante diz respeito à média de criação de conselhos por ano. Entre 1990 e 2002 a média anual foi de 1,16, enquanto de 2003 a 2010 foi de 2,28, praticamente o dobro.

Quanto à obrigatoriedade, cabe destacar que apenas 11 conselhos, ou seja, 28\%, são confirmadamente obrigatórios. Os demais não puderam ser classificados, haja vista a impossibilidade de identificação da obrigatoriedade na legislação consultada. Optou-se, neste caso, por não se deduzir a não obrigatoriedade, mas destacar a ausência da informação.

A este respeito, vale ressaltar que, embora muitos autores afirmem que a previsão de formação de conselhos em áreas como saúde, assistência social e criança e adolescente decorra da Constituição Federal, ao analisá-la com maior rigor identificou-se que ela não faz nenhuma referência expressa à organização da participação popular em forma de conselho. O que a Constituição Federal estabelece é a participação social como diretriz, mas, em todos os casos analisados, a Carta Magna remete à lei a regulamentação de como esta participação irá funcionar.

Ao identificarmos cada uma das leis que regulamentam as distintas políticas públicas, verifica-se que é obrigatória a criação de conselhos como forma de organização da participação social na saúde, meio ambiente, recursos hídricos, assistência social, segurança alimentar, criança e adolescente, alimentação escolar, fiscalização do Fundeb, proteção dos direitos do idoso, política agrícola e política urbana.

O que se observa, porém, é que, mesmo nas áreas em que os conselhos não são expressamente obrigatórios, houve um incremento na conformação desses espaços pelos estados e municípios. Especialmente porque grande parte da nova sistemática de gestão das políticas públicas brasileira adotou fundos de repasse de verbas para desenvolvimento específico daquela política. Assim, além do orçamento advindo dos tributos específicos dos estados e municípios, em muitas áreas o governo federal apoia o desenvolvimento de ações por meio de fundos.

Quanto à composição e paridade, se observa que 44\% dos conselhos federais no Brasil são bipartites não paritários; enquanto $28,9 \%$ são bipartites paritários. A porcentagem de conselhos tripartites não paritários é idêntica aos de conformação múltipla, 10,5\%, enquanto apenas $5,25 \%$, o correspondente a dois conselhos, são tripartites paritários, conforme se pode observar nos gráficos a seguir.

Observa-se que $52 \%$ dos conselhos federais são "não paritários". No entanto, isso não significa, necessariamente, que a representação governamental nestes fóruns seja maior. As vezes, inclusive, é menor, sendo a maioria de representação social.

Outra constatação é de que mais de $65 \%$ dos conselhos federais têm forma de representação vinculada, o que equivale dizer que os representantes são recomendados diretamente pelas organizações da sociedade civil, ainda que os critérios internos de recomendação variem (Draibe, 1998). 
Gráfico 2

Classificação dos conselhos federais quanto à composição

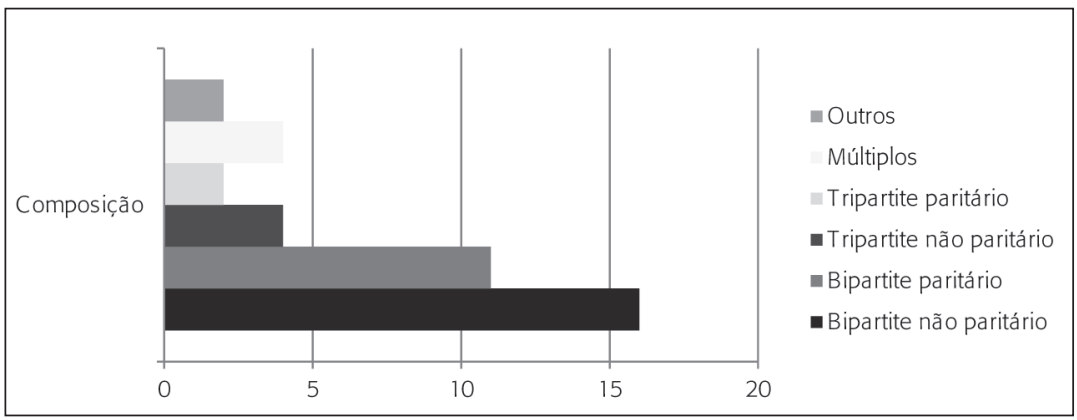

Fonte: Buvinich (2012).

Gráfico 3

Classificação dos conselhos federais quanto à natureza da representação

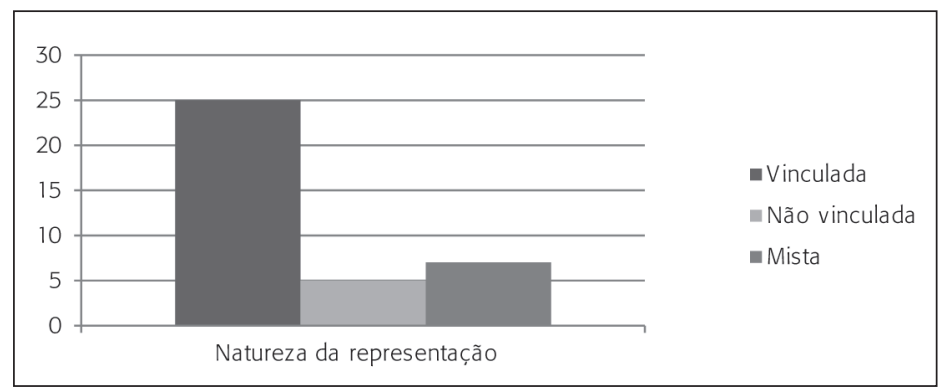

Fonte: Buvinich, 2012.

Quanto à capacidade decisória, se observa que, do total de conselhos federais, 18 são deliberativos, enquanto 16 são apenas consultivos, o que representa, respectivamente, 47\% e $42 \%$. Dos consultivos, se observa que sete deles possuem também a competência de fiscalização expressamente mencionada na lei que o regula.

Quanto à competência fiscalizadora, vale a pena mencionar que se restringe ao monitoramento das atividades determinadas pela norma, sem significar necessariamente um poder sancionador.

Em síntese, se verifica que, dos atuais 36 conselhos federais, 44\% foram criados entre 2003 e 2010, ressaltando a diretriz participativa implementada pelo governo do ex-presidente Luiz Inácio Lula da Silva. A maioria dos conselhos, 20 dos 36, tem formação não paritária, o que não significa necessariamente uma sub-representação social.

Por último, se constata que a maioria dos conselhos federais possui competência deliberativa, tendo o poder (dever) de decidir sobre o direcionamento das políticas, prioridades de investimento e aprovação orçamentária, como nas áreas da saúde e assistência social. 


\subsection{Conselhos municipais}

Da análise transversal dos conselhos municipais implantados nas diversas políticas foi possível identificar características gerais, capazes de proporcionar vestígios de padrões ou tendências regionais, bem como viabilizar conclusões preliminares.

No total, no ano de 2009, o Brasil contabilizou 43.156 conselhos municipais. Destaca-se que não estão contabilizados os conselhos federais e estaduais. Há de se destacar, também, que as distintas políticas investigadas pelo Munic/2009 não cobrem a totalidade das políticas para as quais existe o modelo de conselho implantado. Isso significa dizer que o total apresentado é, certamente, inferior ao total real. Somados aos conselhos federais, o Brasil possui hoje, ao menos, 43.192 conselhos.

Quanto ao número de conselhos municipais implantados, verifica-se que os que têm maior percentual total de implantação são os Conselhos de Assistência Social, presentes em 99\% dos municípios, seguidos dos Conselhos de Alimentação Escolar (CAEs), com 98\% dos municípios brasileiros, cerca de 5.466. Em seguida vêm os conselhos de saúde, com 97\%, e os conselhos do Fundeb, com 94\%.

O conselho com menor percentual de implantação é o de Lésbicas, Gays, Bissexuais, Travestis e Transexuais (LGBT). É também o mais recente entre os conselhos nacionais, e o último a ser criado no governo do ex-presidente Lula, em dezembro de 2010.

Outro dado importante é que somente $28 \%$ dos conselhos brasileiros são de formação obrigatória. Essa obrigatoriedade, ao contrário do que algumas vezes se afirma, não advém diretamente da Constituição. Como ressaltado, há que se distinguir a obrigatoriedade de participação social, esta constitucional, da obrigatoriedade de implementação de conselhos, esta em geral advinda de leis.

Importante constatação diz respeito à correlação direta entre a obrigatoriedade legal de implantação e o grau de implementação dos respectivos conselhos. Assim, dos nove conselhos com maior percentual de implantação, oito são obrigatórios. Excetua-se apenas o conselho de educação, em sexta posição.

Quanto à concentração dos conselhos, a análise transversal dos dados demonstra que há variação em razão do tipo de conselho (q 4 e 5). No entanto, o maior percentual de conselhos está concentrado no Sudeste e Sul, já os menores no Norte e Nordeste. Apesar disso, verifica-se que as regiões possuem ao menos um conselho de cada tipo, com exceção dos conselhos de LGBT.

Estão no Sul e no Sudeste os conselhos criados há mais tempo. Ainda que não existam dados para todos os conselhos, observa-se que os conselhos do Nordeste são mais recentes, tendo havido um acréscimo bastante acentuado de implantação nos últimos anos.

Em todas as áreas pesquisadas observou-se que houve acréscimo no número de conselhos implantados durantes os anos consultados. Exceção apenas para os conselhos de assistência social do Centro-Oeste, que decresceram entre 2005 e 2009 (IBGE, 2010a:56). O mapa da concentração regional de implementação dos conselhos no Brasil pode ser assim representado: 


\section{Figura 1}

\section{Concentração regional dos conselhos implantados}

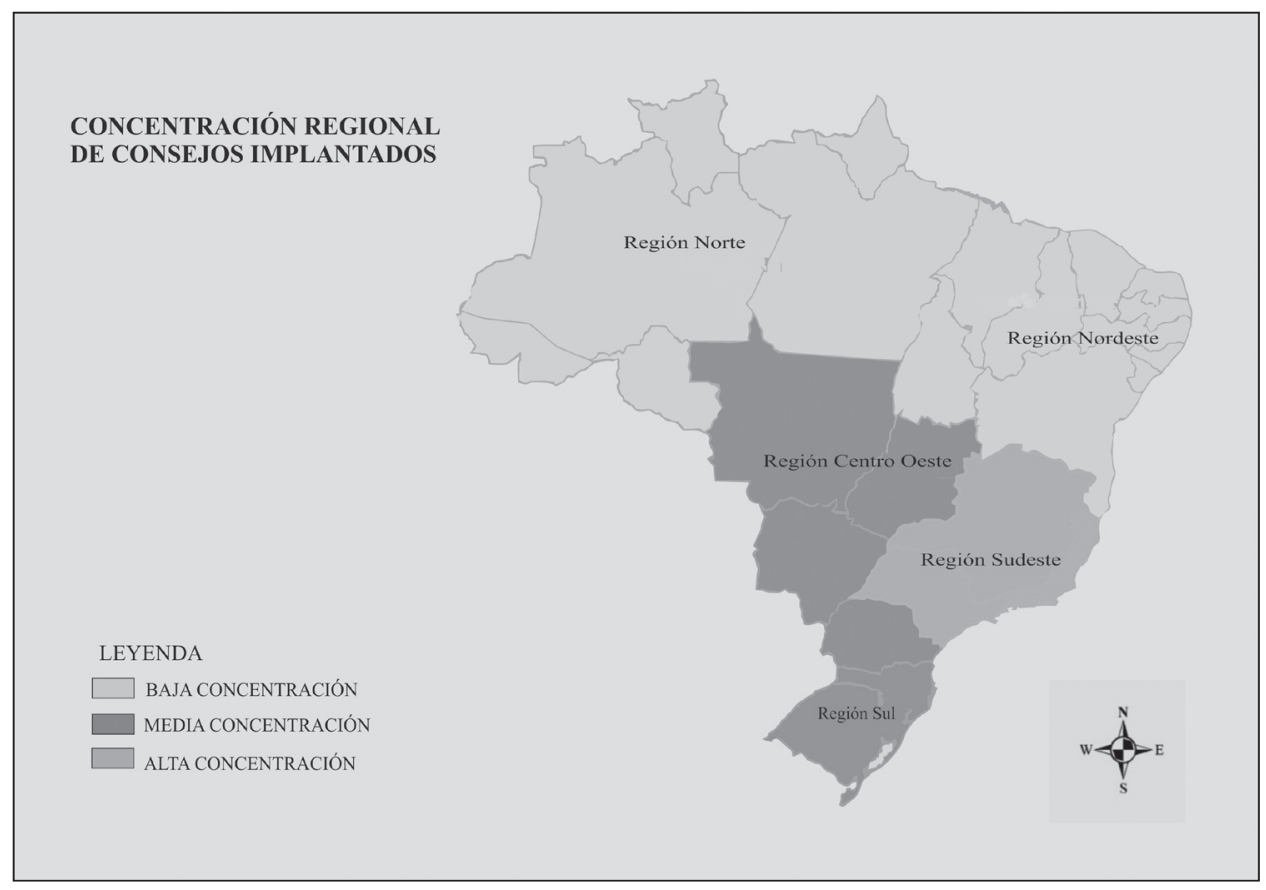

Fonte: Buvinich (2012).

Quanto à paridade observa-se que a maçante maioria dos conselhos municipais brasileiros é paritária (tabela 2 no anexo). O resultado contrasta com aquele encontrado para os conselhos federais, que possuem maioria não paritária.

Importante observação - já mencionada anteriormente — diz respeito à falta de dados sobre a composição da representação nos conselhos não paritários. Isso porque a falta de paridade, ao contrário do que pode parecer em um primeiro momento, não significa, necessariamente, uma sub-representação social, ou uma maior pressão representativa do governo, pelo simples fato de haver conselhos com maior representação social.

Quanto à concentração proporcional de conselhos paritários, verifica-se que o Nordeste possui o maior índice de conselhos paritários, seguido com grande diferença pela região Norte. A região com o menor percentual de paridade em seus conselhos é o Sul, seguido do Centro-Oeste (quadros 6 e 7 no anexo).

Como dito, não se pode presumir que a maior quantidade de conselhos não paritários representa uma menor representação social. Mas é um dado interessante para aprofundamento, uma vez que a constatação de maior representação governamental em conselhos dessas regiões pode ser importante para futuras pesquisas que avaliem a efetividade desses conselhos.

O mapa da concentração proporcional de conselhos paritários no Brasil pode ser assim representado: 
Figura 2

Concentração regional de conselhos paritários

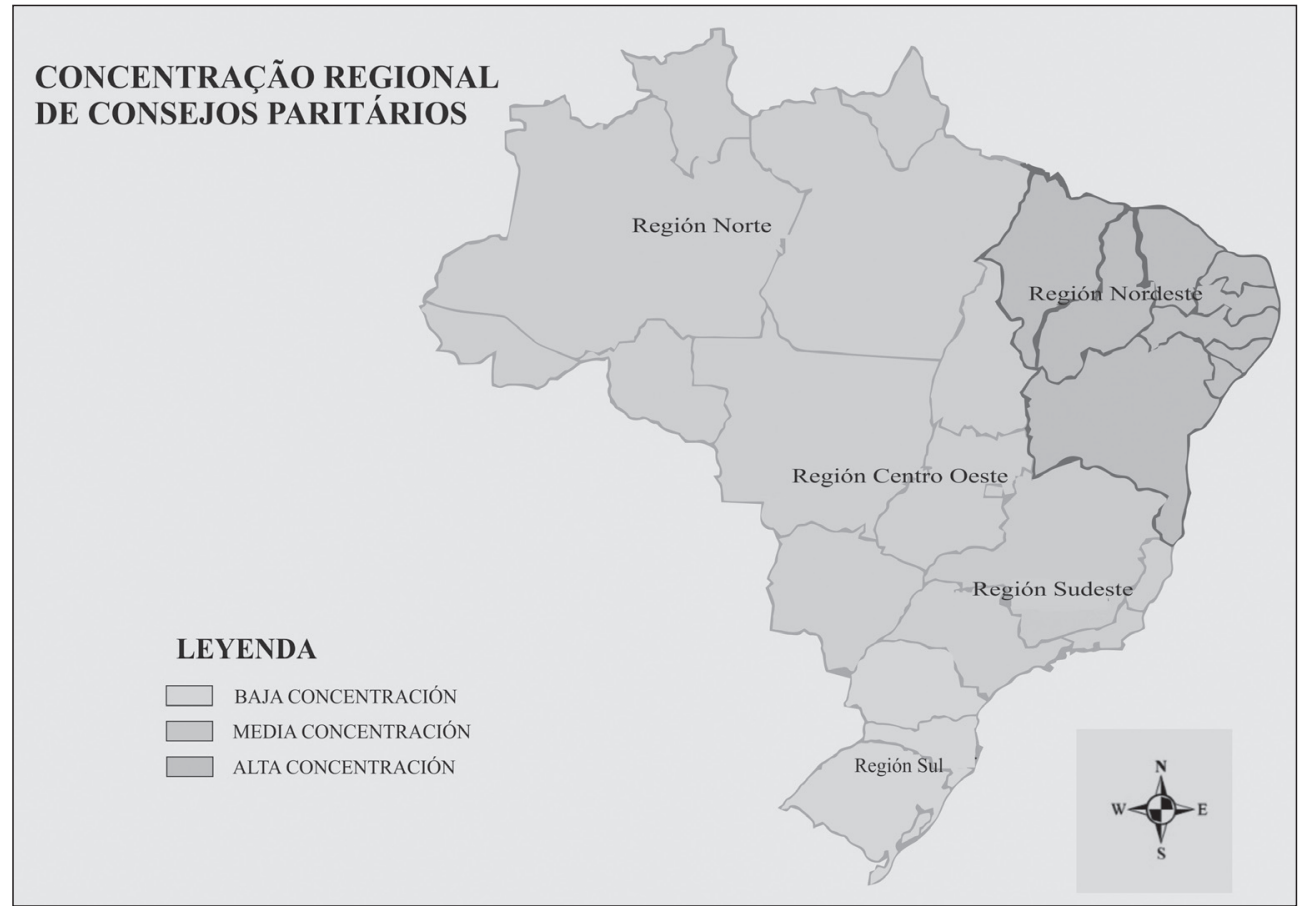

Fonte: Buvinich (2012).

Quanto à capacidade decisória, constata-se que a maioria dos conselhos municipais é deliberativa (quadros 9 e 10 no anexo). O percentual de conselhos consultivos é bastante próximo dos deliberativos. Isso porque a deliberação presume também a capacidade consultiva.

Ao contrastar-se, porém, a capacidade decisória dos conselhos federais com o ano de criação, verifica-se a grande tendência do governo do ex-presidente Lula em privilegiar os conselhos consultivos (quadro 8 no anexo). Observa-se que a grande maioria dos conselhos deliberativos foi criada na década de 1990. A partir de 2003, apesar de ter havido um grande incremento na quantidade de conselhos, a maioria deles é apenas consultiva. Ainda assim, aqueles que têm competência deliberativa, em sua maioria, foram criados ainda em 2003, e o processo de mobilização social para construção da respectiva política nacional já existia há anos.

Contraditoriamente, a maioria dos conselhos municipais criados no Nordeste durante o mesmo período foi deliberativa. Quiçá, porque houve nesta época um incremento na tardia municipalização de políticas básicas, como educação, saúde, assistência social, que são, todas elas, legalmente deliberativas. A presente pesquisa não visa responder diretamente esta questão, mas levanta o debate sobre uma possível tendência - encabeçada pelo modelo federal e seguida pelas regiões Sul e Sudeste — de restrição das competências dos conselhos, ainda que 
os dados municipais absolutos conflitem com a afirmação.

Das competências apuradas, verifica-se que a mais restrita é a normativa. Em todas as áreas pesquisadas o menor percentual sempre esteve relacionado à capacidade normativa dos conselhos. Ainda que se percebam desvios em conselhos específicos, verifica-se uma tendência de que os conselhos com maior percentual de implantação tenham também maior percentual de capacidade normativa.

Quanto à concentração regional dos conselhos com capacidade deliberativa, observa-se o grande predomínio da região Nordeste. Na maior parte das áreas pesquisadas, o Nordeste é a região com maior concentração proporcional de conselhos deliberativos. Assim, configura-se uma curiosa situação: apesar de ser a região com menores índices percentuais de implantação de conselhos - ou seja, as demais região possuem, proporcionalmente, um número maior de municípios com conselhos - , o Nordeste possui um maior número de conselhos paritários e deliberativos.

Teria tal fato relação com a contemporaneidade dos conselhos criados? Ou seria apenas reflexo da tardia municipalização de políticas básicas que possuem na sua política a capacidade deliberativa como diretriz obrigatória? Seria o quadro nordestino reflexo das políticas da década de 1990? O mapa da concentração proporcional dos conselhos com maior capacidade deliberativa no Brasil pode ser assim representado:

\section{Figura 3}

\section{Concentração regional da maior proporção de conselhos deliberativos}

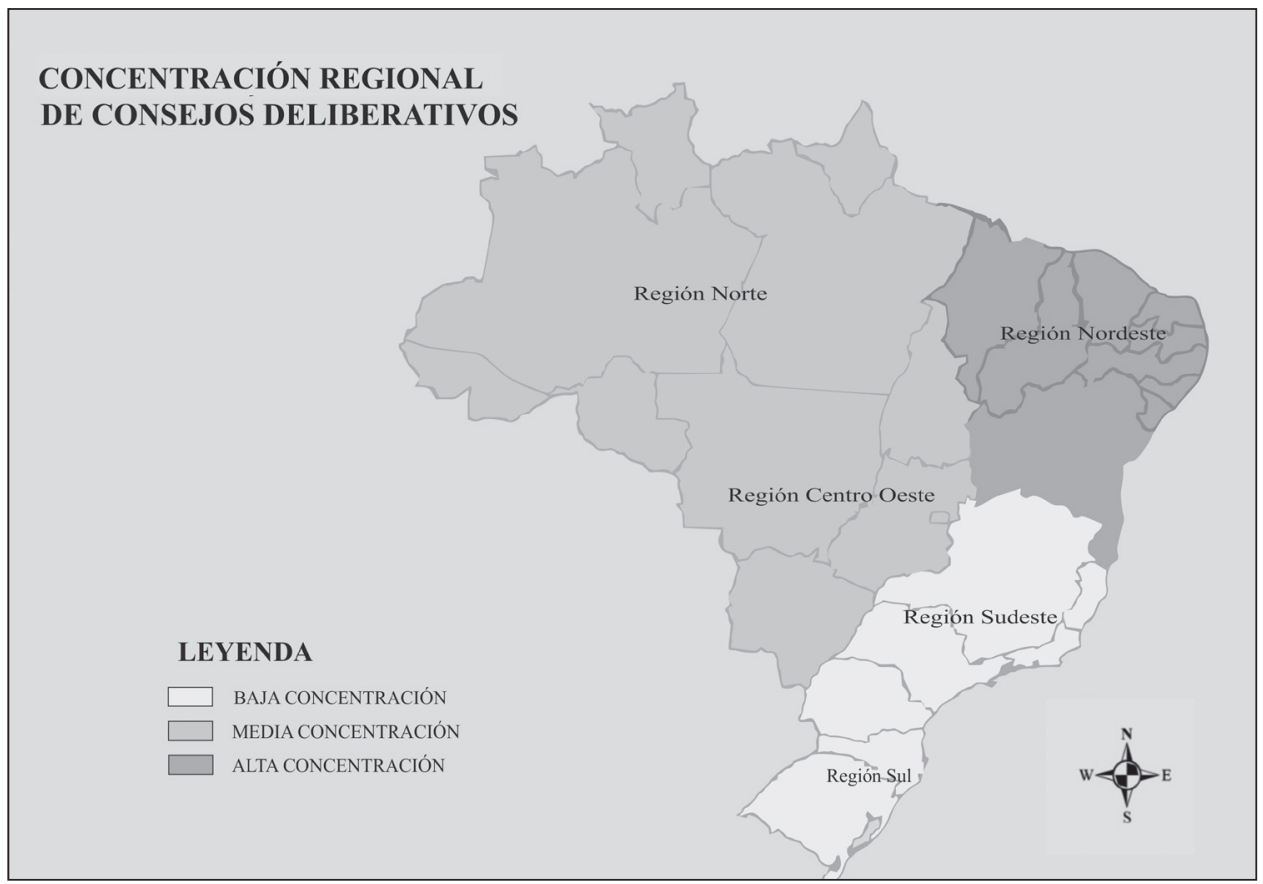

Fonte: Buvinich, 2012. 


\section{Conclusão}

O desenvolvimento dos conselhos gestores no Brasil passou por distintas fases, desde conselho de notáveis, uma espécie de assessoria consultiva especializada, seguido pelos conselhos populares, nos quais a discussão se circunscrevia à ampliação dos direitos (sociais e políticos), chegando aos atuais conselhos gestores de políticas e programas, espaços institucionalizados de participação política cuja função é incidir nas políticas públicas setoriais, produzindo decisões a partir da ampla discussão com setores da sociedade civil.

Mas exatamente qual formato têm os conselhos municipais brasileiros e como eles estão implantados?

Inicialmente, cabe destacar que não há uma regulamentação genérica que padronize as implantações de conselhos como espaço de gestão participativa. A forma de exercício dessa participação possui distintos formatos, o que faz com que os modelos implementados variem não apenas de política para política, mas também de região para região.

Para que a análise das características gerais de implantação dos conselhos municipais de gestão de políticas e programas no Brasil fosse possível, o passo inicial foi a identificação das principais características de configuração desses espaços.

Nesse sentindo, verificou-se que a questão da natureza da representação; da composição e paridade, da capacidade decisória, bem como da obrigatoriedade de instituição são elementos que possuem estreita relação com as avaliações de efetividade deliberativa e cumprimento do papel democratizante destacado aos conselhos, e são estas as características variantes que fazem com que as distinções de implementação sejam tão acentuadas.

O primeiro dado levantado na pesquisa foi referente à obrigatoriedade de constituição de conselhos como instrumento de gestão das respectivas políticas públicas (ou dos programas).

Nesse sentindo, o debate teórico de fundo relaciona-se à possibilidade de a obrigatoriedade deslegitimar o espaço público de participação. Autores como Demo (1996) são enfáticos ao afirmar que os ditos espaços devem ser conquistados para que sejam efetivos. A liberdade concedida seria inevitavelmente controlada.

Contrapondo essa leitura, aliamo-nos a Avritzer (2009), para quem a sociedade política deve ser o condutor da institucionalização dos espaços de participação. Entendemos que a institucionalização conduzida pelo Estado não deslegitima per se a participação, mas concretiza uma segurança jurídica necessária à efetividade da participação. A legitimação estaria mais afeta ao processo de discussão, e representação, do que à condução da institucionalização. Em outras palavras, a legitimação está na forma de apropriação do espaço e não na condução da sua institucionalização.

Identificar a obrigatoriedade de instituição dos conselhos brasileiros foi quiçá o aspecto de maior dificuldade prática no desenvolvimento desta pesquisa. Isso porque, como já destacado em outros momentos, a identificação da informação exigiu a análise dos instrumentos jurídicos regulamentadores das políticas setoriais. Ocorre que a falta de padronização na instituição desse espaço, apontada na introdução deste trabalho, faz com que a especificação da obrigatoriedade 
não seja determinada na política nacional em alguns setores; em outros, na lei de criação do conselho federal; em outros casos ainda, em resoluções ou portarias, ou seja, regulamentações internas dos conselhos federais. A identificação exigiu, portanto, uma ampla e detida varredura nos instrumentos normativos de cada uma das 36 políticas federais pesquisadas.

Verificou-se que as áreas que seguramente determinam a obrigatoriedade de criação de conselhos estaduais e municipais são 11. Como dito, não há um critério para esta definição. Ainda que não existam estudos sobre o assunto, nossa hipótese é de que a obrigatoriedade de se adotar o conselho como instrumento de gestão obrigatório está relacionada à força de mobilização e estruturação da proposta de concretização da política nacional. Seria, portanto, fruto de mobilização social.

Quanto aos dados levantados, verifica-se que a maioria das políticas e programas brasileiros (44\%) não obriga os estados e municípios a instituir conselhos. Ou seja, a maioria dos conselhos brasileiros não é obrigatória e sua instituição fica condicionada à discricionariedade dos gestores estaduais e municipais.

No entanto, a maior proporção de implantação está diretamente relacionada a esta obrigatoriedade. Em outras palavras, possuem maior índice de implantação os conselhos obrigatórios. Ainda assim, não há nenhum conselho implantado em 100\% dos municípios (tabela 1).

Em termos regionais, a pesquisa também identificou que a maior concentração proporcional de conselhos implantados está na região Sudeste; seguida das regiões Sul e Centro-Oeste, com um índice de implantação mediano; seguidas do Norte e Nordeste, com os menores índices de implantação.

A representação e a paridade constituem questões de relevância nevrálgica para o funcionamento adequado desse espaço. Isso porque, como teorizado por Cohen, Bohman e Habermas, a igualdade entre os cidadãos livres é fator fundamental para que os debates (as discussões) ocorram, e sejam inclusivos.

A constatação de que a região Sul possui os menores índices de paridade causa certa surpresa, pois essa região tem grande tradição democrática participativa, especialmente pelo desenvolvimento dos orçamentos participativos. No entanto, não é possível identificar, com os dados disponíveis, se esta falta de paridade se dá em razão de uma eventual super-representação social. O aprofundamento do estudo relacionando as características institucionais da região com a efetividade deliberativa seria bastante elucidativo.

A heterogeneidade na composição dos conselhos, o respeito às diferenças e a adesão a projetos específicos, construídos a partir do debate construtivo, são condições necessárias à eficácia das ações dos conselhos e à consequente ampliação democrática. "É do confronto argumentativo e da tentativa de diálogo entre grupos que defendem interesses distintos, e por vezes claramente antagônicos, que o conselho extrai sua força" (Tatagiba, 2002:62).

O processo deliberativo leva então à última característica estruturante dos conselhos de políticas e programas: a capacidade decisória. Nesse sentido, vale destacar a distinção ressaltada por Teixeira (2008:232): "Mientras el concepto de decisión remite al resultado de un proceso que involucra la elección u opción entre alternativas; la noción de deliberación se refiere a la calidad del proceso que lleva a la decisión". 
O reconhecimento de que o sucesso de um conselho não está restrito unicamente ao seu poder decisório, e sim a um conjunto de elementos que conjugam pluralidade representativa, paridade, qualidade do processo deliberativo (da discussão), não afasta, porém, a importância da deliberação enquanto preceito legal profundamente impactante.

A capacidade deliberativa (o poder de decisão) é apontada pela maioria da doutrina como a efetiva partilha de poder político e o grande diferencial conferido aos conselhos na reforma constitucional. Sem essa capacidade, muitos acreditam que os conselhos continuariam a exercer o papel de "conselho de notáveis" do início do século passado.

A pesquisa identificou que a maioria dos conselhos brasileiros (municipais e federais) é deliberativa, mas chama atenção o crescimento do número de conselhos consultivos implantados.

Em publicação do Ipea (2012), os pesquisadores ressaltam que tem se verificado alta efetividade deliberativa em conselhos do tipo consultivo. De acordo com a publicação, o sucesso poderia ser atribuído à natureza da participação, ou seja, a forma de seleção dos conselheiros; e à capacidade de estabelecer parcerias com instituições intelectuais, políticas, agências de financiamento internacional e instituições sociais.

A interpretação feita sugere que os conselhos consultivos possuem uma capacidade articuladora ampla, capaz de mobilizar atenção, recursos e ações (políticas e sociais). O sucesso deste tipo de conselho estaria então condicionado à sua capacidade de obter compromissos públicos, seja do governo ou da sociedade civil.

A questão que se coloca é até que ponto esta seria uma tendência de modelo; e até que ponto seria uma forma de restringir a participação política ou de ampliar a efetividade deliberativa.

Os dados recolhidos nesta pesquisa confirmam que as regiões Sudeste e Sul do Brasil, regiões que tradicionalmente possuem contemporaneidade, encabeçando tendências, possuem os menores índices de conselhos com capacidade deliberativa. Aliado ao dado de que a maioria dos conselhos federais criados nos últimos anos foi consultivo, poder-se-ia estar diante de uma transformação no modelo institucional dos conselhos brasileiros.

Em conclusão, pode-se afirmar que o modelo conselhista de gestão de políticas e programas no Brasil não só se consolidou nos últimos nove anos, como se ampliou. Os estudos especializados (Fung e Wright, 2003; Luchmann, 2007; Avritzer, 2009; Farias, 2007 e 2010, apud Avritzer, 2010:97) indicam relação direta entre os arranjos institucionais e a efetividade deliberativa, motivo pelo qual o constante monitoramento das características gerais de implantação dos conselhos configura-se essencial, não apenas para formar uma macrovisão da sistemática de gestão das políticas públicas, mas principalmente para se identificar qual estrutura institucional empregada nos conselhos gestores produz os melhores resultados.

Esta estruturação ainda é um processo em andamento, no qual as diversidades históricas, sociais e econômicas dos municípios marcam as distinções de desenvolvimento regionais.

O que se pode afirmar é que os conselhos são hoje, dentre os diversos tipos de formas de participação social adotadas no Brasil, um método de gestão de políticas públicas, especialmente as de cunho social. Como tal, ao mesmo tempo que representa a consolidação prática de um direito socialmente reivindicado, reflete as variedades de estilos e formas de gestão. 
As diversidades de configuração, de amplitude, de organização e de potencial deliberativo dos conselhos advêm e espelham, ou seja, são ao mesmo tempo causa e consequência da heterogeneidade de desenvolvimento das regiões nacionais.

Dado que o modelo institucional sempre está inserido em um contexto político influenciado por uma cultura política, o estabelecimento de modelos ideais altera-se em razão das distintas realidades econômicas, sociais e culturais.

A identificação da existência de padrões regionais, bem como a identificação sobre uma possível tendência de alteração do padrão de modelo indicado, mais do que respostas, incita novas perguntas e propostas de estudos, mas dá um passo em direção à prática da sistematização das informações de gestão nacional.

O avanço no desenvolvimento do ajuste de modelos em razão de culturas próprias visa contribuir para que esses espaços públicos, fruto de um processo nacional de redemocratização, frutifiquem em resultados cada vez mais visíveis, redistributivos, justos, eficientes, influenciando concretamente para a construção de uma sociedade mais equilibrada.

\section{Referências}

AVRITZER, Leonardo. A dinâmica da participação local no Brasil. São Paulo: Cortez, 2010.

AVRITZER, Leonardo. Participatory institutions in democratic Brazil. Baltimore: The Johns Hopkins University Press, 2009.

AVRITZER, Leonardo. Teoria democrática e deliberação pública. Lua Nova, n. 49, p. 25-46, 2000. Disponível em: <www.periodicos.capes.gov.br>. Acesso em: 8 ago. 2011.

BOHMAN, James; REHG, William. Deliberative democracy: essays on reason and politics. EUA: MIT Press, 1997.

BRASIL. Secretaria Nacional de Articulação Social. Conselhos nacionais. Brasília: Secretaria-Geral da Presidência da República, 2010.

BUVINICH, Danitza P. R. Caracterización general de la actual implantación de los consejos gestores municipales de políticas y programas en Brasil. Dissertação (mestrado) — Universidad Complutense de Madrid, Madri, 2012.

CARVALHO, Maria do Carmo A. A.; TEIXEIRA, Ana Cláudia (Org.). Conselhos gestores de políticas públicas. São Paulo: Pólis, 2000. Disponível em: <www.polis.org.br/obras/arquivo_68.pdf>. Acesso em: 28 fev. 2012.

COHEN, Joshua; SABEL, Charles. Directly-deliberative poyarchy. European Law Journal, v. 3, n. 4, p. 313-342, 1997.

COHN, Amélia. Participação social e conselhos de políticas públicas. Brasília: Cepal/Ipea, 2011.

CÔRTES, Soraya M. V. Arcabouço histórico-institucional e a conformação de conselhos municipais de políticas públicas. Educar, n. 25, p. 143-174, 2005. 
DEMO, Pedro. Participação é conquista. 3. ed. São Paulo: Cortez, 1996.

DOMBROWISKI, Osmir. Os conselhos vistos por fora: um estudo sobre a institucionalização dos Conselhos Municipais. In: SEMINÁRIO NACIONAL MOVIMENTOS SOCIAIS, PARTICIPAÇÃO E DEMOCRACIA, 2007, Florianópolis. Anais... Florianópolis: UFSC, 2007. Disponível em: <www. sociologia.ufsc.br/npms/osmir_dombrowski.pdf>. Acesso em: 23 mar. 2012.

DRAIBE, Sônia. A nova institucionalidade do sistema brasileiro de políticas sociais: os conselhos nacionais de políticas setoriais. Caderno de Pesquisa Nepp, n. 35, p. 1-26, 1998. Disponível em: <www.nepp.unicamp.br/index.php?p=52>. Acesso em: 14 fev. 2012.

FUNG, Archon; WRIGHT, Erik Olin. Deepening democracy: institutional innovations in empowered participatory governance. Londres: Verso, 2003.

GOHN, Maria da Glória. Conselhos gestores e participação sociopolítica. 2. ed. São Paulo: Cortez, 2003.

GOHN, Maria da Glória. Papel dos conselhos gestores na gestão pública. INFORMATIVO Cepam, Conselhos municipais das áreas sociais, v. 1, n. 3, p. 7-17, 2001.

IBGE. Instituto Brasileiro de Geografia e Estatística. Perfil dos municípios brasileiros 2009 — assistência social. Pesquisa de Informações Básicas Municipais. Rio de Janeiro: IBGE, 2010a.

IBGE. Instituto Brasileiro de Geografia e Estatística. Perfil dos municípios brasileiros 2009. Pesquisa de Informações Básicas Municipais. Rio de Janeiro: IBGE, 2010. Disponível em: <WWW.ibge.gov. br/home/estatistica/.../perfilmunic/2009/munic2009.pdf>. Acesso em: 30 ago. 2011.

IPEA. Instituto de Pesquisa Econômica Aplicada. Objetivos de desenvolvimento do milênio [relatório de acompanhamento]. Brasília: Ipea, 2007.

IPEA. Instituto de Pesquisa Econômica Aplicada. Participação social como método de governo: um mapeamento das "interfaces socioestatais" nos programas federais. [Comunicado Ipea no 132, de 25 de janeiro de 2012]. Brasília: Ipea, 2012. Disponível em: <www.ipea.gov.br/portal/images/ stories/PDFs/comunicado/120125_comunicadoipea132.pdf>. Acesso em: 11 abr. 2012.

LUCHMANN, Lígia H. H. A representação no interior das experiências de participação. Lua Nova, n. 70, p. 139-170, 2007.

TATAGIBA, Luciana. Os consellhos gestores e a democratização das políticas públicas no Brasil. In: DAGNINO, E. Sociedade civil e espaços públicos no Brasil. São Paulo: Paz e Terra, 2002. p. 47-103.

TEIXEIRA, Ana Cláudia. Desafíos de la construcción democrática en Brasil: participación. São Paulo: Instituto Pólis, 2008.

Danitza Passamai Rojas Buvinich é doutoranda em administração pública e governo pela Universidade Complutense de Madri, mestre em administração pública pela mesma universidade e servidora da Agência Nacional de Vigilância Sanitária. E-mail: danipassamai@gmail.com.br. 


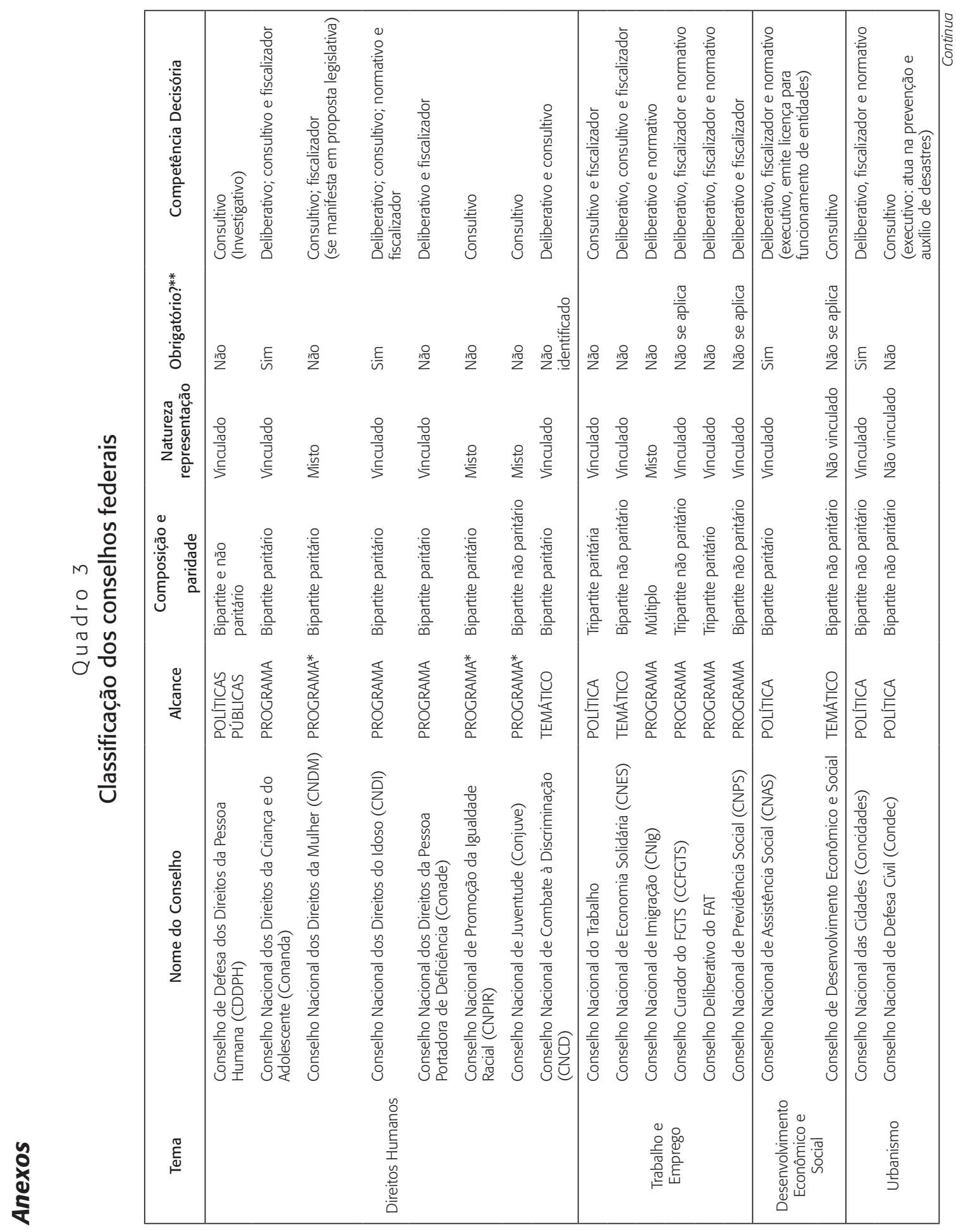

Rev. Adm. Pública - Rio de Janeiro 48(1):55-82, jan./fev. 2014 


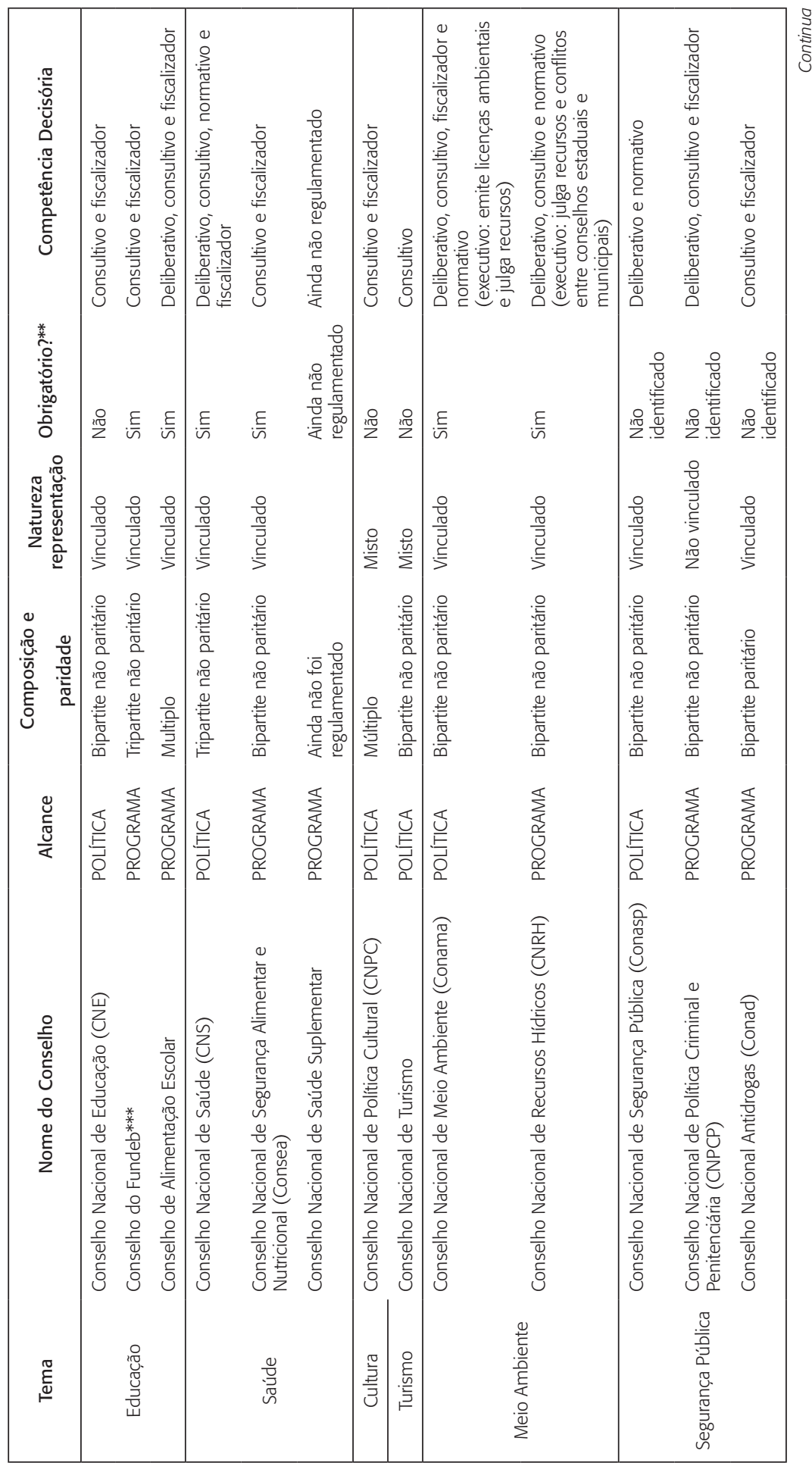

Rev. Adm. Pública - Rio de Janeiro 48(1):55-82, jan./fev. 2014 

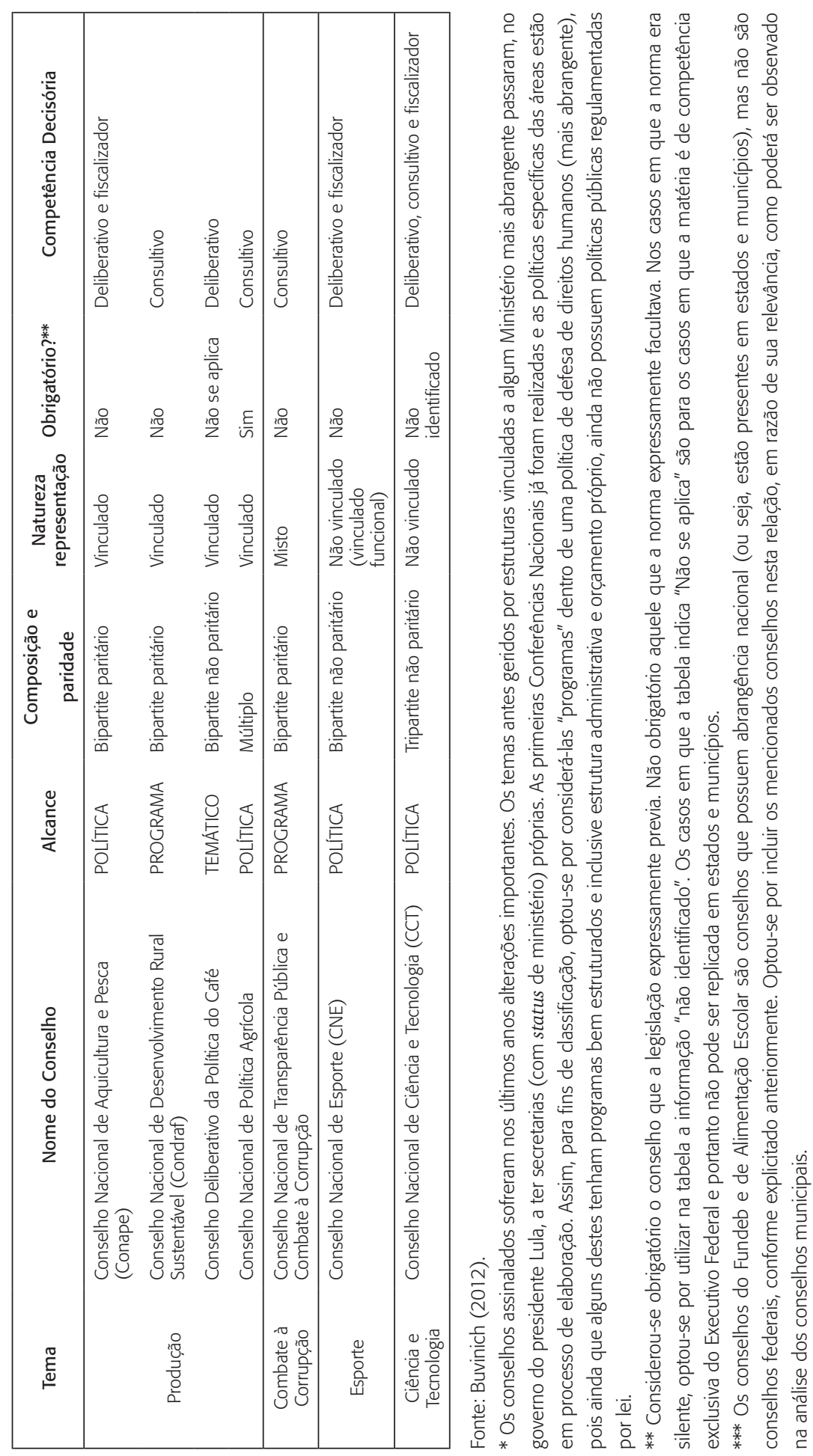
Tabela 1

Relação de conselhos com maior percentual de implantação nacional

\begin{tabular}{|c|c|c|c|}
\hline \multicolumn{2}{|r|}{ Conselhos } & \multicolumn{2}{|c|}{ Percentual de implantação e total absoluto } \\
\hline 1) & Assistência Social & 1) & $99 \%(5.527)$ \\
\hline 2) & CAE & 2) & $98 \%(5.466)$ \\
\hline 3) & Saúde & 3) & $97 \%(5.417)$ \\
\hline 4) & Fundeb & 4) & $94 \%(5.267)$ \\
\hline 5) & Criança e Adolescente & 5) & $91 \%(5.084)$ \\
\hline 6) & Educação & 6) & $79 \%(4.403)$ \\
\hline 7) & Meio Ambiente & 7) & $56 \%(3.124)$ \\
\hline 8) & Cidades & 8) & $43 \%(2.373)$ \\
\hline 9) & Idoso & 9) & $35 \%(1.974)$ \\
\hline 10) & Cultura & 10) & $25 \%(1.372)$ \\
\hline 11) & Esporte & 11) & $11 \%(623)$ \\
\hline 12) & Mulher & 12) & 10,67\% (594) \\
\hline 13) & Segurança & 13) & $10 \%(579)$ \\
\hline 14) & Deficiente & 14) & $9 \%(490)$ \\
\hline 15) & Transporte & 15) & 6\% (328) \\
\hline 16) & Juventude & 16) & $5 \%(303)$ \\
\hline 17) & Igualdade Racial & 17) & $3 \%(148)$ \\
\hline 18) & Direitos Humanos & 18) & $1 \%(79)$ \\
\hline 19) & GLBT & 19) & $0,07 \%(4)$ \\
\hline
\end{tabular}

Fonte: Buvinich (2012).

Quadro 4

Concentração regional dos conselhos brasileiros quanto à proporção de implementação

\begin{tabular}{|lcccccccc|}
\hline \multicolumn{1}{|c}{ Classe } & Educação & Cultura & Esporte & Cidades & Transporte & $\begin{array}{c}\text { Criança } \\
\text { Adolescente }\end{array}$ & Segurança & $\begin{array}{c}\text { Igualdade } \\
\text { Racial }\end{array}$ \\
\hline $\begin{array}{l}\text { Região com } \\
\text { maior percentual }\end{array}$ & Sudeste & Sudeste & Sul & Sul & Sul & $\begin{array}{c}\text { Sul e Centro- } \\
\text { Oeste }\end{array}$ & $\begin{array}{c}\text { Centro- } \\
\text { Oeste }\end{array}$ & $\begin{array}{c}\text { Sudeste } \\
\begin{array}{l}\text { Região com } \\
\text { menor percentual }\end{array}\end{array}$ \\
\hline
\end{tabular}

Fonte: Buvinich (2012). 
Quadro 5

Concentração regional dos conselhos brasileiros quanto à proporção de implementação

\begin{tabular}{|c|c|c|c|c|c|c|c|c|c|}
\hline Classe & $\begin{array}{c}\text { Meio } \\
\text { Ambiente }\end{array}$ & $\begin{array}{c}\text { Direitos } \\
\text { Humanos }\end{array}$ & Idoso & Saúde & Mulher & Juventude & Deficiente & LGBT & $\begin{array}{c}\text { Assistência } \\
\text { Social }\end{array}$ \\
\hline $\begin{array}{c}\text { Região } \\
\text { com maior } \\
\text { percentual }\end{array}$ & Sudeste & Nordeste & Sudeste & Sul & & Sudeste & Sudeste & Centro & Sudeste \\
\hline $\begin{array}{c}\text { Região } \\
\text { com menor } \\
\text { percentual }\end{array}$ & Nordeste & $\begin{array}{c}\text { Centro- } \\
\text { Oeste }\end{array}$ & Nordeste & Norte & & Nordeste & Norte & Sul & Centro-Oeste \\
\hline
\end{tabular}

Fonte: Buvinich (2012).

Tabela 2

Relação de conselhos com maior percentual proporcional de paridade

\begin{tabular}{|c|c|c|}
\hline & Conselhos & Percentual de paridade \\
\hline & Assistência Social & $97 \%$ \\
\hline & Criança e Adolescente & $97 \%$ \\
\hline & Idoso & $97 \%$ \\
\hline & Saúde & $96 \%$ \\
\hline 5) & Deficiente & $94 \%$ \\
\hline & Educação & $89 \%$ \\
\hline & Juventude & $89 \%$ \\
\hline & Meio Ambiente & $88 \%$ \\
\hline & Habitação & $88 \%$ \\
\hline 10) & Mulher & $87 \%$ \\
\hline & Cidades & $86 \%$ \\
\hline 12) & Igualdade Racial & $85 \%$ \\
\hline 13) & Direitos Humanos & $85 \%$ \\
\hline 14) & Cultura & $84 \%$ \\
\hline 15) & Esporte & $79 \%$ \\
\hline 16) & Segurança & $77 \%$ \\
\hline 17) & Transporte & $77 \%$ \\
\hline 18) & LGBT & $75 \%$ \\
\hline
\end{tabular}

Fonte: Buvinich (2012). 
Quadro 6

Concentração regional dos conselhos brasileiros quanto à paridade

\begin{tabular}{|c|c|c|c|c|c|c|c|c|}
\hline Classe & Educação & Cultura & Esporte & Cidades & Transporte & $\begin{array}{c}\text { Criança } \\
\text { Adolescente }\end{array}$ & Segurança & $\begin{array}{l}\text { Igualdade } \\
\text { Racial }\end{array}$ \\
\hline $\begin{array}{l}\text { Região } \\
\text { com maior } \\
\text { percentual }\end{array}$ & Nordeste & Nordeste & $\begin{array}{c}\text { Norte/ } \\
\text { Centro-Oeste }\end{array}$ & Nordeste & Nordeste & $\begin{array}{l}\text { Nordeste/ } \\
\text { Sudeste }\end{array}$ & $\begin{array}{c}\text { Norte/ } \\
\text { Centro-Oeste }\end{array}$ & $\begin{array}{l}\text { Norte/ } \\
\text { Nordeste }\end{array}$ \\
\hline $\begin{array}{l}\text { Região } \\
\text { com menor } \\
\text { percentual }\end{array}$ & Sul & Sul & Sul & Norte & $\begin{array}{l}\text { Centro- } \\
\text { Oeste }\end{array}$ & $\begin{array}{l}\text { Sul/Centro- } \\
\text { Oeste }\end{array}$ & Sul & $\begin{array}{l}\text { Centro- } \\
\text { Oeste }\end{array}$ \\
\hline
\end{tabular}

Fonte: Buvinich (2012).

Quadro 7

Concentração regional dos conselhos brasileiros quanto à paridade

\begin{tabular}{|c|c|c|c|c|c|c|c|c|c|}
\hline Classe & $\begin{array}{c}\text { Meio } \\
\text { Ambiente }\end{array}$ & $\begin{array}{l}\text { Direitos } \\
\text { Humanos }\end{array}$ & Idoso & Saúde & Mulher & Juventude & Deficiente & LGBT & $\begin{array}{l}\text { Assistência } \\
\text { Social }\end{array}$ \\
\hline $\begin{array}{l}\text { Região } \\
\text { com maior } \\
\text { percentual }\end{array}$ & $\begin{array}{l}\text { Nordeste/ } \\
\text { Sudeste }\end{array}$ & $\begin{array}{l}\text { Centro- } \\
\text { Oeste }\end{array}$ & Nordeste & Nordeste & Norte & Nordeste & Norte & $\begin{array}{l}\text { Igual em } \\
\text { todas as } \\
\text { regiões }\end{array}$ & $\begin{array}{c}\text { Sul e } \\
\text { Sudeste }\end{array}$ \\
\hline $\begin{array}{l}\text { Região } \\
\text { com menor } \\
\text { percentual }\end{array}$ & Sul & Sul & $\begin{array}{l}\text { Sudeste/ } \\
\text { Norte }\end{array}$ & Sul & $\begin{array}{l}\text { Centro- } \\
\text { Oeste }\end{array}$ & $\begin{array}{l}\text { Centro- } \\
\text { Oeste }\end{array}$ & $\begin{array}{l}\text { Sudeste/ } \\
\text { Centro- } \\
\text { Oeste }\end{array}$ & - & $\begin{array}{l}\text { Centro- } \\
\text { Oeste }\end{array}$ \\
\hline
\end{tabular}

Fonte: Buvinich (2012).

Quadro 8

Relação de conselhos federais por ano de criação e capacidade decisória

\begin{tabular}{|lcc|}
\hline \multicolumn{1}{|c}{ Nome do Conselho } & Ano de criação & Capacidade decisória \\
\hline Conselho Nacional de Política Criminal e Penitenciária (CNPCP) & 1984 & DELIBERATIVO \\
Conselho Curador do FGTS (CCFGTS) & 1990 & DELIBERATIVO \\
Conselho Deliberativo do FAT & 1990 & DELIBERATIVO \\
Conselho Nacional de Meio Ambiente (Conama) & 1990 & DELIBERATIVO \\
Conselho Nacional de Saúde (CNS) & 1990 & DELIBERATIVO \\
Conselho Nacional de Política Agrícola & 1991 & CONSULTIVO \\
Conselho Nacional de Previdência Social (CNPS) & 1991 & DELIBERATIVO \\
Conselho Nacional dos Direitos da Criança e do Adolescente (Conanda) & 1991 & DELIBERATIVO \\
Conselho Nacional de Assistência Social (CNAS) & 1993 & DELIBERATIVO \\
Conselho Nacional de Imigração (CNIg) & 1993 & DELIBERATIVO \\
Conselho Nacional de Educação (CNE) & 1995 & CONSULTIVO \\
\hline
\end{tabular}




\begin{tabular}{|c|c|c|}
\hline Nome do Conselho & Ano de criação & Capacidade decisória \\
\hline Conselho Nacional Do Trabalho & 1995 & CONSULTIVO \\
\hline Conselho Nacional de Ciência e Tecnologia (CCT) & 1996 & DELIBERATIVO \\
\hline Conselho Nacional de Recursos Hídricos (CNRH) & 1997 & DELIBERATIVO \\
\hline Conselho Nacional de Esporte (CNE) & 1998 & DELIBERATIVO \\
\hline Conselho Nacional de Desenvolvimento Rural Sustentável (Condraf) & 1999 & CONSULTIVO \\
\hline Conselho Nacional dos Direitos da Pessoa Portadora de Deficiência (Conade) & 1999 & DELIBERATIVO \\
\hline Conselho Nacional dos Direitos do Idoso (CNDI) & 2002 & DELIBERATIVO \\
\hline Conselho de Desenvolvimento Econômico e Social (CDES) & 2003 & CONSULTIVO \\
\hline Conselho Deliberativo da Política do Café & 2003 & DELIBERATIVO \\
\hline Conselho dos Direitos da Pessoa Humana (CDDPH) & 2003 & CONSULTIVO \\
\hline Conselho Nacional das Cidades (Concidades) & 2003 & DELIBERATIVO \\
\hline Conselho Nacional de Aquicultura e Pesca (Conape) & 2003 & DELIBERATIVO \\
\hline Conselho Nacional de Economia Solidária (CNES) & 2003 & DELIBERATIVO \\
\hline Conselho Nacional de Promoção da Igualdade Racial (CNPIR) & 2003 & CONSULTIVO \\
\hline Conselho Nacional de Segurança Alimentar e Nutricional (Consea) & 2003 & CONSULTIVO \\
\hline Conselho Nacional de Transparência Pública e Combate à Corrupção (CTPCC) & 2003 & CONSULTIVO \\
\hline Conselho Nacional de Turismo (CNT) & 2003 & CONSULTIVO \\
\hline Conselho Nacional de Defesa Civil (Condec) & 2005 & CONSULTIVO \\
\hline Conselho Nacional de Juventude (Conjuve) & 2005 & CONSULTIVO \\
\hline Conselho Nacional de Política Cultural (CNPC) & 2005 & CONSULTIVO \\
\hline Conselho Nacional Antidrogas (Conad) & 2006 & CONSULTIVO \\
\hline Conselho Nacional dos Direitos da Mulher (CNDM) & 2008 & CONSULTIVO \\
\hline Conselho Nacional de Segurança Pública (Conasp) & 2009 & DELIBERATIVO \\
\hline Conselho Nacional de Combate à Discriminação (CNCD) & 2010 & DELIBERATIVO \\
\hline Conselho Nacional de Saúde Suplementar & 2010 & $\begin{array}{c}\text { AINDA NÃO REGULA- } \\
\text { MENTADO }\end{array}$ \\
\hline
\end{tabular}

Fonte: Buvinich (2012).

Quadro 9

\section{Concentração regional dos conselhos brasileiros quanto à capacidade deliberativa}

\begin{tabular}{|lcccccccc|}
\hline \multicolumn{1}{|c}{ Classe } & Educação & Cultura & Esporte & Cidades & Transporte & $\begin{array}{c}\text { Criança } \\
\text { Adolescente }\end{array}$ & Segurança & $\begin{array}{c}\text { Igualdade } \\
\text { Racial }\end{array}$ \\
\hline Maioria & Delibera & Consulta & Consulta & Delibera & Consulta & Delibera & Consulta & Consulta \\
$\begin{array}{l}\text { Região com maior } \\
\text { percentual }\end{array}$ & Nordeste & $\begin{array}{c}\text { Centro- } \\
\text { Oeste }\end{array}$ & Sul & Nordeste & Nordeste & Norte/ & Nordeste & Nordeste \\
$\begin{array}{l}\text { Região com menor } \\
\text { percentual }\end{array}$ & $\begin{array}{c}\text { Centro- } \\
\text { Oeste/Norte }\end{array}$ & Sul & Sudeste & Sul & Centro & Sudeste & Sul & Sudeste \\
\hline
\end{tabular}

Fonte: Buvinich (2012). 
Quadro 10

Concentração regional dos conselhos brasileiros quanto à capacidade deliberativa

\begin{tabular}{|c|c|c|c|c|c|c|c|c|c|}
\hline Classe & $\begin{array}{c}\text { Meio } \\
\text { Ambiente }\end{array}$ & $\begin{array}{l}\text { Direitos } \\
\text { Humanos }\end{array}$ & Idoso & Saúde & Mulher & Juventude & Deficiente & LGBT & $\begin{array}{l}\text { Assistência } \\
\text { Social }\end{array}$ \\
\hline Maioria & Delibera & Delibera & Delibera & Delibera & Delibera & Consulta & Delibera & $\begin{array}{l}\text { Delibera } \\
\text { Consulta }\end{array}$ & Delibera \\
\hline $\begin{array}{l}\text { Região } \\
\text { com maior } \\
\text { percentual }\end{array}$ & Norte & $\begin{array}{l}\text { Centro- } \\
\text { Oeste/ } \\
\text { Nordeste }\end{array}$ & $\begin{array}{c}\text { Norte/ } \\
\text { Nordeste }\end{array}$ & Nordeste & Nordeste & Nordeste & Nordeste & - & Nordeste \\
\hline $\begin{array}{l}\text { Região } \\
\text { com menor } \\
\text { percentual }\end{array}$ & $\begin{array}{l}\text { Centro- } \\
\text { Oeste }\end{array}$ & Sul & Sudeste & Norte & $\begin{array}{l}\text { Centro- } \\
\text { Oeste }\end{array}$ & $\begin{array}{l}\text { Centro- } \\
\text { Oeste }\end{array}$ & $\begin{array}{l}\text { Centro- } \\
\text { Oeste }\end{array}$ & - & Norte \\
\hline
\end{tabular}

Fonte: Buvinich (2012). 